\title{
Pneumopericardium Leading to Cardiac Tamponade in a Patient with Lung Cancer
}

\author{
Ahmad Al-Taweel $^{1} \quad$ Adil Ayub $^{1} \quad$ Chyun-yin Huang ${ }^{1} \quad$ Sadiq Rehmani ${ }^{1}$ Adnan Al-Ayoubi ${ }^{1}$ Faiz Y. Bhora ${ }^{1}$ \\ ${ }^{1}$ Department of Thoracic Surgery, Mount Sinai St. Luke's and Mount \\ Sinai West, New York, United States \\ Thorac Cardiovasc Surg Rep 2016;5:13-15.

\begin{abstract}
Address for correspondence Faiz Y. Bhora, MD, FACS, Department of Thoracic Surgery, Mount Sinai St. Luke's and Mount Sinai West, 1000 Tenth Avenue, 2B-07, New York, NY 10019, United States (e-mail: fybhora@chpnet.org).
\end{abstract}

\author{
Abstract \\ Keywords \\ - pneumopericardium \\ - cardiac tamponade \\ - pericardial window \\ - video-assisted \\ thoracoscopic surgery
}

Pneumopericardium resulting in cardiac tamponade in patients with lung cancer is not documented. We report a case of squamous cell carcinoma of the lung complicated by pneumopericardium and subsequent cardiac tamponade. The patient underwent an urgent pericardial window with rapid improvement in symptoms. We discuss the possible pathogenesis and treatment options for this rare condition.

\section{Case Presentation}

A 56-year-old man with severe chronic obstructive pulmonary disease and 40 pack year smoking history presented with chronic cough and hemoptysis. Computed tomography (CT) chest revealed a 7-cm right hilar mass (-Fig. 1A). A small amount of air measuring 3 to $4 \mathrm{~mm}$ was incidentally noted within the pericardium (-Fig. 1B). An endobronchial ultrasound-guided biopsy was subsequently performed for diagnosis and staging. Final histopathology revealed squamous cell carcinoma. Shortly thereafter, the patient presented to the emergency department with progressive shortness of breath and worsening chest pain. Cardiac examination was remarkable for muffled heart sounds. A chest X-ray confirmed pneumopericardium (-Fig. 2A). Transthoracic echocardiography was technically difficult due to the presence of pericardial air and showed respiratory flow variation of greater than $25 \%$ across the mitral and tricuspid valves consistent with echocardiographic evidence of cardiac tamponade. Repeat CT scan showed an increase in pneumopericardium to $18 \mathrm{~mm}$ (-Fig. 2B).

An urgent pericardial window procedure was planned. We chose video-assisted thoracoscopic surgery (VATS) procedure to evaluate possible tumor invasion into the atrium and assess surgical resectability. An arterial line was placed prior to induction to monitor hemodynamic parameters. Given hemodynamic stability, we proceeded with right-sided VATS pericardial window procedure under single-lung ventilation. On creating the window, significant amount of frothy air was released from within the pericardial sac. The tumor was seen to be directly invading the posterior wall of the left atrium and unresectability was confirmed. Patient had an uneventful recovery from surgery with significant improvement in symptoms of chest pain and shortness of breath. A chest drain was left in place and removed the following day.

The patient went on to receive definitive chemoradiation therapy. He was doing well at 6-month follow-up with good response to treatment. Follow-up imaging showed no residual pneumopericardium.

\section{Discussion}

Documented cases of pneumopericardium in patients with lung cancer are extremely rare with only nine such cases described in the literature. ${ }^{1-8}$ Concurrent pneumomediastinum has been reported in one case $\mathrm{e}^{5}$ and coexisting pneumothorax was reported in three other cases. This is the first reported case of lung cancer complicated by pneumopericardium with subsequent development of cardiac tamponade.

Reported causes of pneumopericardium include trauma, fistula formation between the pericardium and adjacent aircontaining structures, barotrauma, pericardial infections, and iatrogenic trauma. ${ }^{8}$ Lung cancer leading to pneumopericardium is proposed to be caused by one of the following received

November 18, 2015

accepted after revision

December 3, 2015

published online

January 29, 2016
DOI http://dx.doi.org/

10.1055/s-0036-1571360. ISSN 2194-7635.
@ 2016 Georg Thieme Verlag KG
Stuttgart · New York

License terms

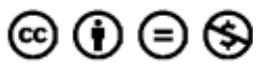



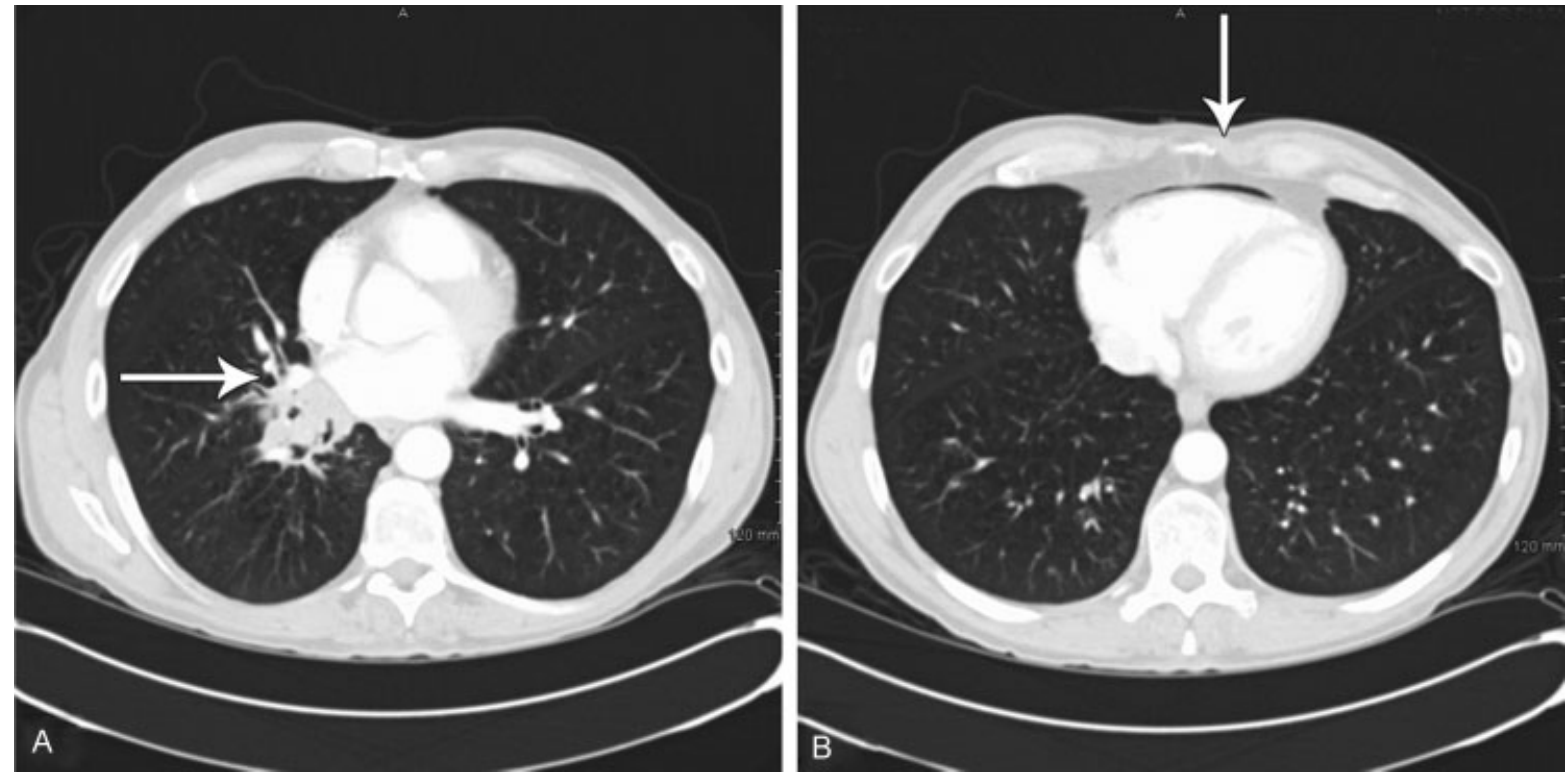

Fig. 1 (A) Right hilar necrotic tumor invading the left atrium. (B) 3- to 4-mm pneumopericardium.
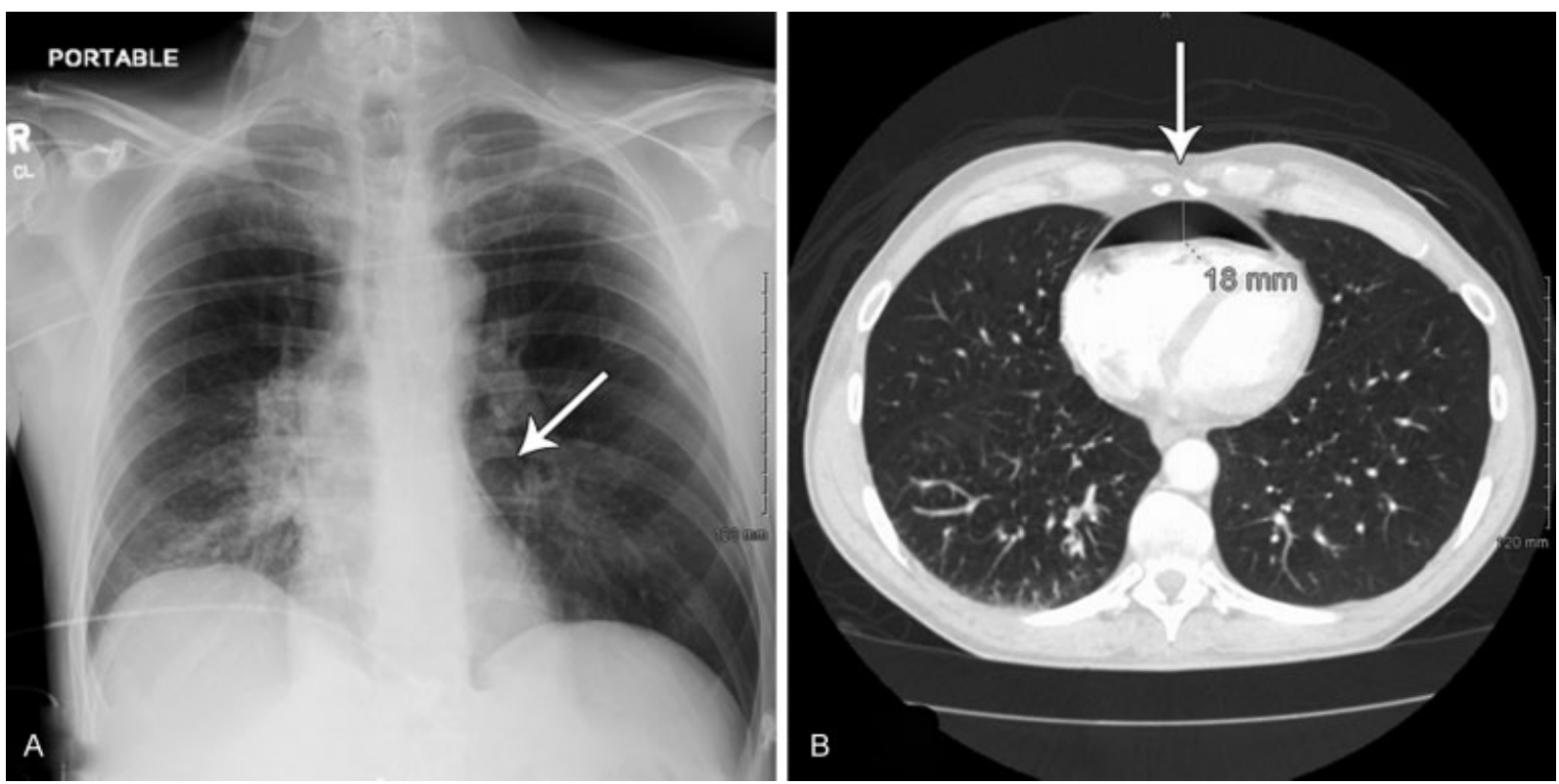

Fig. 2 (A) Chest X-ray on admission consistent with pneumopericardium.

(B) CT scan shows increase in pneumopericardium to $18 \mathrm{~mm}$.

mechanisms: (1) formation of a bronchopericardial fistula by direct pericardial invasion of a necrotic tumor; (2) iatrogenic trauma caused by procedures such as thoracocentesis or bronchoscopy; and (3) rupture of a bulla into the pericardium through a necrotic focus. ${ }^{1,7}$ In this case, the tumor was seen to be directly invading the left atrium, tipping the mechanism in favor of a bronchopericardial fistula as the most likely cause of the pneumopericardium.

Patients with small, stable, asymptomatic pneumopericardium may be treated conservatively with close monitoring to prevent escalation to cardiac tamponade. Prompt decompression is advised if there are progressive symptoms, a concurrent pneumothorax, or cardiac tamponade. We made the decision for operative intervention in this patient given his progressing pneumopericardium, worsening symptoms, and echocardiographic evidence of cardiac tamponade.

To our knowledge, this is the first report of a pneumopericardium and pericardial tamponade in a patient with advanced lung cancer. We managed the patient with a VATS pericardial window with good outcome.

\section{Author Contributions}

F. Y. B. takes final responsibility for the content of this manuscript, including the data and analysis. A. A.-T., A. A., and C.-Y. H. contributed to data collection and writing. S. R., A. M. A. and F. Y. B. contributed to patient care, writing, and critical review. 


\section{References}

1 Baydur A, Gottlieb LS. Pneumopericardium and pneumothorax complicating bronchogenic carcinoma. West J Med 1976;124(2): 144-146

2 González-Juanatey C, Vidán Martínez J, González-Juanatey JR. Pneumopericardium complicating bronchogenic carcinoma [in Spanish]. Rev Esp Cardiol 2002;55(2):185

3 Harris RD, Kostiner AI. Pneumopericardium associated with bronchogenic carcinoma. Chest 1975;67(1):115-116

4 Imai A, Ishikawa S, Nakamura R, et al. Pneumopericardium 3 years after lung cancer surgery. Ann Thorac Surg 2008; 85(2):664
5 Kara J, Klimesova S, Pauk N. Pneumomediastinum and pneumopericardium in a patient with squamous cell lung cancer. Arch Bronconeumol 2015;51(5):249-250

6 Katzir D, Klinovsky E, Kent V, Shucri A, Gilboa Y. Spontaneous pneumopericardium: case report and review of the literature. Cardiology 1989;76(4):305-308

7 Kim YI, Goo JM, Im JG. Concurrent pneumopericardium and pneumothorax complicating lung cancer: a case report. Korean J Radiol 2000;1(2):118-120

8 Wang L, Song Y, Li X, Peng A. Hydropneumopericardium with metastatic lung carcinoma and pneumonia. Intern Med 2010; 49(24):2709 